ANUARIo de Estudios Medievales

43/2, julio-diciembre de 2013, pp. 695-716

ISSN 0066-5061

doi:10.3989/aem.2013.43.2.07

\title{
MENTALIDADES DE FRANCOS Y BIZANTINOS EN 1204: UNA APROXIMACIÓN
}

\author{
AN APPROACH TO THE MENTALITIES OF FRANKS AND \\ BYZANTINES IN 1204
}

\author{
LAMBROS KOTSALÁS \\ University of Athens - Universidad de Zaragoza
}

\begin{abstract}
Resumen: El ensayo presente tiene como objetivo brindar propuestas novedosas para el tema de la cuarta cruzada y la toma de Constantinopla por los latinos en 1204. Tras polemizar el empleo insatisfactorio existente de los conceptos de los cuales echaremos mano, el autor basándose en herramientas de la historia de las mentalidades trata de arrojar nueva luz sobre la interpretación de la acción de los francos y de los bizantinos. El estudio de lo maravilloso en las fuentes de aquella época nos descubre nuevos aspectos de la capital de Bizancio, con su carácter legendario que la acompaña. Clave principal de toda esta empresa es la interacción del molde conceptual del hombre medio con los incentivos que lo rodean. Si seguimos tal procedimiento, podremos entender el comportamiento individual, la acción humana que determina el devenir histórico. También, podremos atisbar un mundo cristiano dividido, con una estructura de pensamiento parecida y perspectivas contrarias.
\end{abstract}

Palabras clave: cuarta cruzada; historia de las mentalidades; Constantinopla; francos y bizantinos; lo maravilloso.

\begin{abstract}
The object of the present essay is to open up new approaches to the topic of the fourth crusade and the conquest of Constantinople by the Latins in 1204. Apart from the discussion on the problematic recent application of the concepts we are going to address, I have relied on methodological tools for the history of mentalities, attempting to shed new light on the interpretation of the actions of both Franks and Byzantines. The survey on the marvellous in the accounts of that period reveals to us anew the capital of Byzantium, characterized and accompanied by the mythical element. The key of my endeavor is the interaction of the average man's frame of mind with the stimuli surrounding him. In doing so, we will be able to comprehend the individual's demeanor, the human action that determines the historical process. Furthermore, we shall scrutinize a bifurcated Christian cosmos, with similar structure of thought and contrary perspectives.
\end{abstract}

Keywords: fourth crusade; history of mentalities; Constantinople; Franks and Byzantines; the wonderful.

\section{SUMARIO}

1. Notas preliminares.- 2. Las fuentes empleadas: categorización y autores.- 3. La bienvenida.- 4. Conclusiones.-5. Bibliografía citada. 


\section{NOTAS PRELIMINARES}

El historiador se enfrenta casi siempre con la dificultad de concebir de inmediato y en su totalidad el acaecer de las sociedades pasadas. Por eso, este todo se suele fragmentar en categorías subjetivas, a fin de poder volver a representarlo. Esta paradoja ha sido, más o menos así, bosquejada por J. Burckhardt y es su solución acerca de cómo se aproxima a la realidad externa ${ }^{1}$. Pero, además de esto, a veces hay que incluir en este esquema poco flexible el detenimiento cronológico y sentimental por parte del científico en cuestión en el hecho (social) observado. Si tuviésemos que optar por una analogía aclaratoria de todo este procedimiento, elegiríamos la del viaje largo y lleno de aventuras, cuyo protagonista se tiene que parar en muchos sitios hasta poder llegar a su destino final. Dejando de lado las alusiones homéricas y hablando manifiestamente sobre la índole de nuestro enfoque, podemos evocar la proposición de $\mathrm{Ph}$. Abrams: Excursions into the study of mentalite are not a withdrawal from the explanation of history as process; they are a necessary detour in order to arrive there safely ${ }^{2}$.

Para acercarnos, pues, al asunto en cuestión, una historia cultural relacionada con el mundo bizantino resulta una tarea bastante ardua ${ }^{3}$. Desafortunadamente, la percepción monolítica de aspectos culturales en Bizancio, tal es el caso por ejemplo de la "certitud" que habla de la consistent textuality bizantina frente al predominio de la oral culture occidental, como señalaba en su tiempo con cierta ironía A. Kazhdan ${ }^{4}$, desanima a los audaces. De todos modos, dicho vacío nos ha atraído la atención. Y es en este punto donde conviene preguntarnos: ¿es ético, si deseamos dar una contestación a las necesidades actuales de la investigación, oscurecer las "aguas transparentes" dentro de las cuales se movían los historiadores anteriores?

Sin perder de vista, pues, la tendencia interdisciplinaria, consideramos que tenemos que actuar en favor de nuestra tarea. La tarea de reconstruir para el momento presente. Así pues, pensamos en cambiar el prisma mediante el cual se veía la fuente. En el texto presente intentaremos trabajar creativamente, puesto que un tema como el imaginario y las mentalidades requiere la presencia de la imaginación o intuición razonada del investigador, aun a riesgo de que nos pongamos a resolver nudos gordianos. Predecimos que respeta-

1 J. Burckhardt, The civilization, p. 19.

$2 \mathrm{Ph}$. Abrams, History, sociology, p. 12. También, en la nota núm. 31 de la misma página: "Which is not to say that the journey will not be a prolonged and a wondering one".

3 Véase al respecto las observaciones agudas de L. Mavromatis en Historia bizantina, pp. 65-70.

4 A. Kazhdan, Latins and Franks, p. 83. 
remos los textos estudiados sin tratar de extraer de ellos resultados ilógicos ${ }^{5}$. Así pues, como sinopsis programática viene a nuestra mente la advertencia de I. Lotman:

los textos ${ }^{6}$, como formaciones más estables (...) al trasladarse a otro contexto cultural, se comportan como un informante trasladado a una nueva situación comunicativa: actualizan aspectos antes ocultos de su sistema codificante?

\section{LAS FUENTES EMPLEADAS: CATEGORIZACIÓN Y AUTORES ${ }^{8}$}

Las fuentes que hemos elegido estudiar son dos relatos acabados en torno a la segunda década del siglo XIII. Sus autores, un caballero franco y un político bizantino, fueron testigos oculares de la toma de Constantinopla en 1204. En cuanto a los sucesos siguientes de la ocupación de la capital bizantina, con el pánico omnipresente por toda la ciudad, adquirieron su información en parte oralmente.

Ya que no podemos tocar minuciosamente todos los ámbitos geográficos de la presencia latina en Romania, nos ceñiremos sobre todo a la zona capitalina9. Pero más allá de esto, la razón sustancial de nuestro enfoque parti-

5 E. Mitre, Historiografía y mentalidades, p. 20.

6 Entendidos con el sentido más amplio de la palabra.

7 I. M. Lotman, La semiótica de la cultura, http://www.ugr.es/ mcaceres/entretextos/pdf/ entre2/escritos/escritos2.pdf, [consulta: 20/07/2011].

8 Sobre la fuentes y las traducciones existentes en idiomas de la actualidad, consúltese el sitio web de la Fordham University de New York: http://www.fordham.edu/halsall/byzantium/ alltexts.asp, [consulta: 25/07/2011].

9 Especialmente sobre los hechos políticos que tuvieron lugar desde la predicación de la cuarta cruzada por el papa Inocencio III (verano de1198) hasta su desviación, la toma de Constantinopla y la posteridad con el nuevo equilibrio de poderes formado (1222) se pueden consultar los textos que siguen: primero, la obras históricas del bizantino G. Acropolites (que comprende los años 1203-1261) en la edición de A. Heisenberg, Georgii Acropolitae, Opera

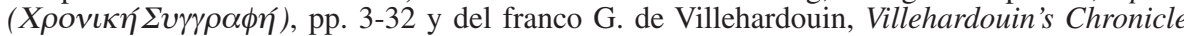
of the fourth crusade and the conquest of Constantinople, pp. 1-133. También, los manuales contemporáneos de historia política de G. Ostrogorsky, Historia del estado bizantino; A. Chri-

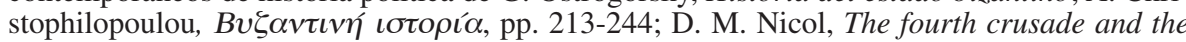
Greek, en Byzantium: Its ecclesiastical history, pp. 275-330; M. Angold, The fourth crusade: event and context; S. Runciman, A history of the crusades; D.E. Queller, The fourth crusade; A. Frolow, La déviation, pp. 168-187; J. Harris, Byzantium and the crusades; J. Philips, The fourth crusade and the sack, pp. 21-28; Th.F. Madden (ed.), The fourth crusade: event. Sobre las baronías y principados de los latinos en Grecia, con el énfasis puesto en el principado de Acaya, véase S. Runciman, Mistra. En cuanto a los inicios del imperio de Niza (Nicea) en Asia Menor, consúltese la tesis doctoral de I. Giarenis, la percepción bizantina en torno a la idea de la "Guerra Sacra" y su aprovechamiento, véase la proposición atrevida, enunciada en la disertación de A. Kolia-Dermitzaki, $O \beta v \zeta \alpha v \tau \iota v o ́ s$ 
cular y minucioso es la ciudad misma, alrededor de cuyo eje se mueven, sueñan y encuentran ${ }^{10}$ los caballeros del norte de Europa que llegaron a participar en su toma, por una parte, y sus habitantes bizantinos, por otra ${ }^{11}$. Y ésta es la apuesta y riesgo más profundo del presente intento, dado que de una manera latente se buscarán, mediante los indicios del pensamiento mitificante que hay en nuestras fuentes, sentimientos y acciones - en la mayoría de los casos con carácter espontáneo y vigencia provisional - tanto inter-estamentales, como inter-"nacionales".

Así pues, el primero de nuestros autores es Robert de Clari (1170$1216)^{12}$, un caballero de pequeña escala que participó en la cuarta cruzada como vasallo de Pierre de Amiens. La narración de su texto, que se titula $L a$ Conquête de Constantinople, abarca desde 1202 hasta 1216. Según la clasificación tradicional, esta obra es una crónica que se preocupa por narrar hechos. Como la mayoría de los escritores que nos dejaron fuentes directas, al menos hasta el pleno Medievo, R. de Clari no se interesaba por encontrar, y conectar entre sí, causas y efectos. En su caso particular, se podría decir que escribía mediante sus sentimientos. Y esto se debe entender literalmente. Era un hombre del común que, además de preservar la hazaña heroica de sus compatriotas, apuntó todo aquello que le pareció digno de asombro.

Por parte de los bizantinos, hemos trabajado con el texto del cortesano Niketas Choniates (1155-1215/6) ${ }^{13}$, que escribió la llamada Historia

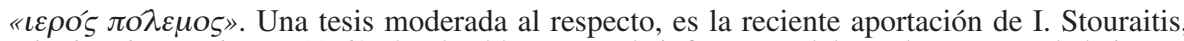
Jihäd and crusade, pp. 11-63, donde el lector puede informarse del estado presente de la investigación sobre el tema. Por último, un texto sumario sobre la historiografía de las cruzadas es el de G. Constable, The historiography, pp. 1-22. Para bibliografía amplia sobre las cruzadas consúltese la nota núm. 3 que hay en la p. 1 del mismo texto. También, véase el sitio web que sigue: http://www.crusades-encyclopedia.com/bibbyzantiumandthecrusades.html, [consulta: 30/07/2011] donde aparecen referencias bibliográficas en cuanto a la relación Bizancio-cruzadas.

10 D.J. Geanakoplos, Byzantine East and Latin West, p. 5.

11 Con la intención de explicar la frase "enfoque particular y minucioso", con respecto también al abanico amplio de los testimonios disponibles del período estudiado, podemos decir que, como se verá unas líneas más abajo, queríamos que el análisis de nuestro razonamiento se basase exclusivamente en dos casos que estuvieran en las antípodas, social, cultural y geográficamente hablando.

12 Sobre R. de Clari, véase R. de Clari, La conquête de Constantinople, trad. J. Dufournet [édition bilingue], Paris, Honoré Champion, 2004, pp. 7-8. También, el prólogo y la introducción, en R. de Clari, The conquest of Constantinople, trad. E. H. McNeal, Nueva York, Columbia University Press, 2005, pp. [no página enumerada para el prólogo], 3-27; D.E. Queller, The fourth crusade, pp. 39, 220; C. Orcástegui, E. Sarasa, La historia en la Edad Media, pp. 219-220.

13 Sobre el autor bizantino véase la introducción y el comentario sobre la traducción, en N. Choniatae, O City of Byzantium, Annals of Niketas Choniates, trad. H. J. Magoulias, Detroit, Wayne State University Press, 1984, pp. ix-xxviii, xxix respectivamente; A.J. Simpson, Before 


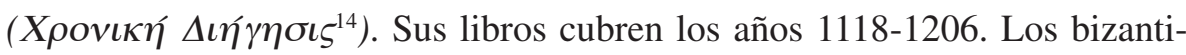
nistas consideran su obra como una Historia conscientemente escrita, en contraposición con las crónicas. Su aspecto estilístico sigue, por lo menos en la superficie, los ejemplos de los historiadores de la Antigüedad. En general, trata de destacar la concatenación de los sucesos, sobre todo en las ocasiones que quiere criticar a algún emperador por razones personales.

En lo concerniente a la formación intelectual de cada uno de nuestros protagonistas, el primero de ellos pudo tener, como máxima educación, relatos novelescos, canciones caballerescas y leyendas vulgarizadas de todo tipo. El segundo, tuvo la suerte de formarse como lector profundizando en textos homéricos, retóricos, evangélicos, de Tucídides etc. Sin embargo, será más preciso utilizar para la obra de ambos autores, en lugar de Crónica o Historia, las palabras relato, fuente [directa], texto, escrito y registro ${ }^{15}$.

\section{LA BIENVENIDA}

Las profecías sibilinas se confirmaron ${ }^{16}$. El hecho de la invasión masiva en Constantinopla fue el momento de la plena exaltación, por un lado, y de la plena humillación, por el otro. Las tropas occidentales pudieron alcanzar su recóndito sueño, pudieron ser los inmediatos herederos del aura atrayente del Oriente cristiano, que se había concentrado en Bizancio. La capital del imperio bizantino era en efecto la tierra de la abundancia, la tierra que el hombre medio del Occidente del siglo XIII estaba convencido de que existía en un lugar situado fuera de su alcance ${ }^{17}$. El pillaje, las violaciones y los sacri-

and after 1204, pp. 189-221; J. Harris, Distortion, sobre todo las pp. 19-21, 25-26. También, D. Queller, The fourth crusade, p. 221; H. Hunger, Byzantinische geisteswelt, pp. 197-201.

14 «Narración crónica», en castellano.

15 En lo concerniente a los problemas de clasificación de las obras históricas bajomedievales, se puede consultar el artículo de B. Guenée, Histoires, annales, pp. 1003, 1008-1009, 1011, 1015-1016. También, véase C. Orcástegui, E. Sarasa, Los géneros históricos, en La historia en la Edad Media, pp. 26-35.

16 Se trata de las esculturas supuestamente proféticas, atribuidas a las Sibilas, fabricadas sobre las columnas del emperador Teodosio y Arcadio que había en el foro de Constantinopla. Según ellas, "de vers Occident venroient une gent haut tondue a costeles de fer, qui Constantinoble conquerroient". Véase el testimonio de R. de Clari, La conquête de Constantinople, p. 182, líneas 17-19. Ibidem, pp. 110-112; D. E. Queller, The fourth crusade, p.101. También, véase el libro instructivo de P. Alphandéry, A. Dupront, La cristiandad, pp. 66-67. En relación con el tema de la catástrofe esperada, creemos que no sería atrevido explicar este fenómeno diciendo que funciona como un eufemismo inverso, como un aval de prosperidad. Véase al respecto el último párrafo del presente artículo.

17 Sobre el tema de la "wonderland" véase los apuntes de F. Graus en Social utopias, pp. 7-9. También, R. de Clari, The conquest of Constantinople, p. 118. 
legios sucedidos los primeros días tras la entrada de los soldados de Jesucristo revelan el estado anímico del momento, esto es el paroxismo de haber encontrado el paraíso terrenal. Quizás por la presencia de lo terreno se soslayaron de momento las preocupaciones espirituales. Todo estaba invertido y todo se permitía $^{18}$. De hecho, Constantinopla era para su época, si podemos concebir la analogía, moult rika terra, según el dux veneciano E. Dandolo ${ }^{19}$.

De esto nos han dejado evidencia tanto N. Choniates como R. de Clari. El primero en su llanto por la pérdida de su ciudad nos describe pormenorizadamente todos los monumentos destruidos. Por el contrario, el caballero francés se detiene a contemplar las maravillas, a calcular su valor y a reproducir las leyendas que conoció de oídas ${ }^{20}$. Es comprensible para el lector actual el hecho de que un lugar como Constantinopla, preñado de estatuas de la Antigüedad y del periodo helenístico, que además disponía de palacios preciosos, de su hipódromo famoso, de templos llenos de mosaicos estilizados e iconostasios de oro, mármol, plata etc., llamara tanto la atención a los cruzados. La capital del imperio bizantino era el apogeo de la urbanización con casi un millón de habitantes, un numero desorbitante para el pleno Medievo $^{21}$.

El propio R. de Clari, impactado, nos deja claramente su testimonio de esto: et virent [los cruzados] tant de gent (...) que sanloit que demis li mondes i fust ${ }^{22}$. Sin embargo, este ambiente urbanizado resultaba horrendo para los caballeros de menor rango, que, contradictoriamente, querían identificarse con ello. Todo era inmenso, desde su perspectiva: le chité qui molt estoit grande et longe et le $e^{23}$. En la crítica lanzada por parte de R. De Clari contra sus superiores, a lo mejor podemos encontrar un indicio apodíctico de la angustia que le sofocaba a él y a sus iguales a principios del siglo XIII: "Es inadmisible que repartan todo el botín los señores de los grandes feudos entre sí sin que

18 Por ejemplo, P. Gounarides, H $\varepsilon \iota \kappa o ́ v \alpha \tau \omega v \Lambda \alpha \tau \iota ́ v \omega v$, en N. G. Moschonas (ed.),

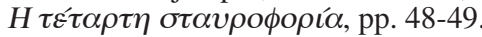

19 P. Alphandéry, A. Dupront, La cristiandad, p. 58. Sin embargo, la frase que hemos reproducido del libro de P. Alphandéry y A. Dupront no corresponde al dialecto veneciano y, por lo tanto, su origen queda sin especificación. La observación al respecto es de N. Moschonas, director emérito del programa de investigación "Byzantium and the West" en el NHRF / Institute of Byzantine Research. Agradezco sinceramente su intervención crítica. También, véase J. Le Goff, Mentalities, en Medieval civilization, pp. 325-361.

20 R. de Clari, La conquête de Constantinople, pp. 29-30, 34.

21 No obstante, este dato numérico se ha puesto en tela de juicio por algunos historiadores. Véase D.E. Queller, The fourth crusade, la nota núm. 46 de la p. 197.

22 R. de Clari, La conquête de Constantinople, p. 162, líneas 30-31.

23 Ibidem, p. 164, líneas 14-15. 
sepamos nosotros nada de ello ${ }^{24}$. Habían empezado ya en Europa occidental los antagonismos entre los mercaderes y el estrato militar. Los más proclives a relegarse social y económicamente eran los caballeros inferiores ${ }^{25}$.

En este punto creemos que es preciso incluir un comentario sobre el papel que desempeñó la capital del nuevo imperio latino. Su función de conservación de preciosidades la convirtió para los militares comunes de la cuarta cruzada en un símbolo que se podía auto-confirmar. Más precisamente, esta dimensión museística que poseía Constantinopla ${ }^{26}$, descubierta en condiciones reales solamente después del paso masivo hacia el interior de la ciudad, despertó un comportamiento que puede parecer paradójico. Consideramos que no sería atrevido hablar de una transformación de Constantinopla en fetiche acompañado por connotaciones sexuales, en términos de la relación guerrero / semental - ciudad / mujer sumisa.

Pero ¿por qué razón fetiche? Por un lado, porque ya antes de conocerla, la capital bizantina había traspasado, a través de su leyenda, la admiración y el valor del contenido al contenedor, esto es, de los objetos materiales a la idea de la ciudad. Se sabía más o menos que Constantinopla era la ciudad de las riquezas. Tras su "abertura en profundidad" este sentimiento genérico preexistente se intensificó concretándose. Lo que queremos decir con todo esto es que la primera causa de la manía catastrófica hacia las maravillas encontradas era esa óptica impuesta sobre la ciudad o, mejor dicho, su mito. La capital de Bizancio, formidable externamente por su vastedad, sus murallas, sus puertas, desorientaba la atención del visitante inacostumbrado que venía de fuera de sus sitios de interés ${ }^{27}$. $Y$ esto se entiende si pensamos un instante en las categorías estéticas dentro de las cuales había crecido el cruzado ordinario de la Europa medieval.

Esta transsilio de calidades era, pues, uno de los primeros casos donde podemos hablar de una continuación productiva entre la realidad y el imaginario, aunque -al menos por el contenido- con efectos destructivos. Pero sigamos con el hilo conductor de nuestro razonamiento. Había también otro lado que, paralelamente al punto anterior, contribuyó a esta dirección de fetichismo lesivo. Era una lectura muy particular que se hizo sobre la obra artística. La situación antes trazada prácticamente denota que

24 “Adont si s'asanlerent li haut home, li rike home, et prisent consel entr'aus, que le menue gent n'en seurent mot ne li povre chevalier de l'ost, que il prenderoient les meilleurs ostex de le vile;". Ibidem, p. 168, líneas 9-12 y ss.; R. de Clari, The conquest of Constantinople, pp. $102,126$.

25 J. Le Goff, Guerriers et bourgeois, pp. 113-136.

26 Constantinopla era "un véritable musée de l'Orient hellénique". G. Dagron, Naissance d'une capitale, p. 36.

27 U. Eco, Il feticismo nell'arte.

ANUARIO de Estudios MEdievales, 43/2, julio-diciembre 2013, pp. 695-716 ISSN 0066-5061, doi:10.3989/aem.2013.43.2.07 
los objetos artísticos per se no pudieron de ningún modo ser reconocidos por sus nuevos propietarios. Una parte del desdén y la manía catastrófica hacia ellos por parte de los cruzados creemos que puede explicarse así. Pero la indiferencia mostrada no nos puede valer como contestación concluyente. La otra parte de la explicación es, a nuestro juicio, la lógica aritmética. Todo se lee en cantidades numéricas. Todo se traduce a valor monetario. El antagonismo dicotómico existente en el objeto, entre su valor estético y su valor monetario, pudo tener en nuestro caso solamente un resultado: su violación cultural.

Un hombre, como era el soldado a pequeña escala de la cuarta cruzada, que desconoce totalmente los aspectos estéticos de un objeto ${ }^{28}$, conecta la razón de ser de una cosa con su papel utilitario y/o valor monetario. Este tipo de "desprecio" pudiera parecer al lector actual una barbarie o un paralogismo. Sin embargo no es así. Por el contrario, era una lectura muy lógica, siendo bien contextualizada para la mayoría de los hombres del pleno Medievo, occidentales y bizantinos. $\mathrm{Y}$ esto lo debemos tener en consideración, si queremos que nuestro entendimiento de las sociedades pasadas sea preciso y objetivo. Por eso no nos tiene que extrañar el hecho de que muchas de las obras de arte que había en Constantinopla se convirtieran en monedas. No se podía reconocer en ellas alguna otra utilidad. Hay que ser exactos pues, cuando hablamos de maravillas admiradas. R. de Clari nos dice en su registro: [se refiere a las riquezas del templo de Hagia Sophía] tous estoit d'argent massis, qui estoit si rikes que on ne peust mie nombrer l'avoir que il valoit. Y unas líneas más abajo: pendoit bien chent lampiers; (...) et si n'i avoit lampier qui ne vausist bien deus chens mars d'argent. ${ }^{29}$. De hecho, así fue: los latinos acuñaron monedas de los objetos metálicos encontrados ${ }^{30}$.

\footnotetext{
28 Argumentos relacionados con la manía catastrófica de los latinos en D.E. Queller, The fourth crusade, p. 149.

29 R. de Clari, La conquête de Constantinople, p. 176, líneas 18-20, 22, 25-26 respectivamente.

30 La deuda debida por parte de los francos a sus compañeros de Venecia no pudo ser, a nuestro juicio, la causa principal de esta acción, puesto que muchos de los caballeros del norte de Europa ya habían pagado la cantidad de dinero estipulada que les correspondía a cada uno a la República de la Laguna. Aquí nos referimos al tratado que firmaron los portavoces de los líderes de la cuarta cruzada con los venecianos en la capital de los últimos el año 1201 para su transporte a Egipto. Véase al respecto, D.E. Queller, The fourth crusade, pp. 9-18 y sobre todo las pp. 41, 47, 49, donde se puede ver el compromiso al que llegaron los jefes de la expedición y no la masa del ejército de los cruzados. Esto se sostiene también en el texto de M. Meschini, The 'four crusades' of 1204, p.33, donde se reconoce solamente la obligación que habían asumido los soldados de Jesucristo de participar en la cruzada y no de prestar sus servicios a Venecia.
} 
N. Choniates, por su parte, lamenta esa pérdida:

y vos, ;oh ciudad, reina de las ciudades!, reliquia de Su Alteza, vos ciudad hospitalaria que eres el canto de los cantos, el ser más esplendoroso y de todos los espectáculos existentes la visión más única (...) ¿Qué consuelo podemos hallar?, ya que estamos desnudos, como si nos hubieran extorsionado de tu seno materno ${ }^{31}$.

Tal pasaje se enmarca dentro de la producción de un género literario floreciente desde comienzos del siglo XIII hasta finales del siglo XV, con la toma de Constantinopla por los turcos otomanos. Es un discurso que se designa "ekfraseis poleon" ("expresiones [oratorias] sobre las ciudades") $)^{32}$. Se hace con intención de alabar a la ciudad bizantina poniendo el énfasis en lo maravilloso que la caracteriza. Hay que recalcar que el autor bizantino en las líneas antes reproducidas (p. 591, línea núm. 25 de la edición crítica de J.-L. van Dieten) se sirve del mecanismo retórico de la asimetría: por un lado "los espectáculos existentes", que como son ordinarios los puede uno detectar fácilmente en el mundo terreno. Por otro lado, esos espectáculos se comparan con algo que no pertenece a la misma categoría que ellos. Se hace referencia, como podemos leer, a una "visión", identificada con Constantinopla (espectáculo ordinario versus visión única). Es bien sabido que las visiones se conectaban en la Edad Media con la presencia de la divinidad. Aparecían a las personas bendecidas. Así, mediante este esquema desequilibrado se logra exaltar a la ciudad desde lo terrenal a lo celestial. Es la ciudad por excelencia, una versión mejorada, podríamos decir, de Jerusalén ${ }^{33}$.

Por último, nos vamos a detener en un detalle del vocabulario empleado, lo cual muy a menudo refleja las oscilaciones de la mentalidad. Con la frase "la visión más única" que N. Choniates dirige a la ciudad nos decidimos a pensar sobre una noción que creemos que era inter-estamental, al menos para la sociedad bizantina de la época. El adjetivo "único" [spanios] que acompaña a la palabra "visión" puede significar dos cosas en griego: o "infrecuente" o "precioso" / "valioso". Parece que había cierta conexión del valor que se atribuía a la visión con su contenido. Lo que era distinto de lo usual disfrutaba del reconocimiento común. A través de una visión peculiar se adquiría prestigio. También, si acentuamos más la segunda opción semántica,

31 Traducción directamente del texto original. Véase, N. Choniatae, Historia (X९оvıки́ $\Delta \iota \eta \gamma \eta \sigma \iota \varsigma)$, ed. J.-L. van Dieten, [CFHB, XI], Berlín-Nueva York, 1975, pp. 591.21-592.28. Un inventario detallado de las obras destruidas nos lo ofrece el autor bizantino en N. Choniatae, $O$ City of Byzantium, pp. 357-362, [647.1-655].

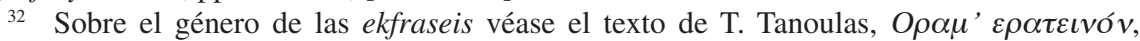
en C. Angelidi (ed.), Byzantium matures, pp. 328-329.

33 G. Dagron, Naissance d'une capitale, p. 387. 
podríamos estimar que había una aceptación general por parte de los hombres medievales de las visiones cristianizadas.

No obstante, para regresar a la previa línea argumental, no es casual que la mayoría de los objetos salvados fueran los relacionados con la religión cristiana. P. Alphandéry y A. Dupront en este punto han hecho una observación genuina. Tal como sostienen, tierras como Constantinopla eran "lugaresreliquias". No solo atraían a los feligreses y/o aventureros por su necesidad de expresar su reverencia hacia los objetos consagrados, y mediante ellos a Dios, sino que se preocupaban por robar - quitar una parte de ellos con el fin de llevarlos consigo a su patria. ¿Cuál era la causa de actuar así? Uno podría inmediatamente decir que lo hacían por razones de puro altruismo, por el amor a su prójimo. Sin embargo, es más probable que esas reliquias desempeñasen el papel del testimonio del viaje de pertinencia realizada ${ }^{34}$. De esto también se denota, por un lado, la índole de transacción que había entre el feligrés y Dios. Era una relación de tipo obligación-derecho. Por otro lado, según apunta A. Gurevich, en sociedades como la del Medievo an object endowed with magical qualities frequently embodies an element of the proprietor: the good fortune of the owners is transferred to the object owned ${ }^{35}$. La posesión de un objeto, en este caso del de la reliquia, se nos presenta como evidencia de prosperidad. El que la encontró no pudo ser nada menos que un hombre elegido, un hombre beneficiado. El destinatario final de esta reliquia suma en su persona el conjunto de sus características beneficiosas, que se heredaron por sus poseedores anteriores.

La idea de la penitencia constreñida violentamente en el subconsciente del cruzado común, cronológicamente después de la decisión del desvío hacia la capital bizantina, re-asoma a la superficie del comportamiento individual. Creemos que es insostenible hablar de Constantinopla-reliquia antes de su ocupación ${ }^{36}$, por la simple razón de que ni siquiera sus propios habitantes tenían información muy "clara" en torno a sus objetos sacros ${ }^{37}$. Lo que más valía para los habitantes de Constantinopla era poseerlos y servirse de sus

34 P. Alphandéry, A. Dupront, La cristiandad, p. 59.

35 A. Gurevich, Historical anthropology, p. 14.

36 Y esto a pesar de que muchos y/o la mayoría de los cruzados hubieran visitado la capital bizantina con sus tesoros religiosos después de su primera conquista, R. de Clari, La conquête de Constantinople, pp. 12-13,31; D. E. Queller, The fourth crusade, p. 204 nota núm. 22 y de la p. 215 la nota núm. 53. Compárese con A. Frolow, La déviation, pp. 172-173. La demostración de nuestra tesis la proporciona F. R. Swietek, Gunther of Pairis, p. 63 y especialmente la nota núm. 114.

37 R. de Clari, The conquest of Constantinople, p. 17; Como se sabe el interés se centró en la reliquias más conocidas, como las de la Pasión, D.E. Queller, The fourth crusade, p. 114. La razón de ser de esta inclinación igual se puede explicar si tomamos en consideración lo que sigue: "Passio Christi fuit ex dolore amara, ex illusione despecta et ex utilitate multiplici 
cualidades profilácticas en los momentos que había alguna guerra. Más bien al referirse a ellos trataban de insertar elementos fantaseados, historias cuyo pasado se perdía dentro del mito. Hay que tener presente que el hombre común del Medievo, estuviera en Occidente o en Oriente, traducía sentimentalmente su ambiente. Alrededor de él había un mundo de significados arcanos y seres sobrenaturales, la existencia de los cuales captaba mágicamente mediante indicios simbólicos.

Ahora bien, conviene echar nuestra mirada al siguiente elemento apodíctico de este entrecruzamiento del imaginario con la realidad que, según nuestra opinión, elucida bien la naturaleza de las mentalidades en cuestión. Podría uno pensar que tras el "descubrimiento" de la ciudad, los invasores se hicieran más sensatos. Esto, como ya hemos apuntado en el caso de las reliquias, no sucedió nunca. Además de esto, podríamos decir que ese modo de entendimiento se exacerbó aún más. Por lo menos esto nos demuestran las digresiones realizadas en el relato de R. de Clari. Veamos unas que, según nuestro parecer, pertenecen a las más interesantes.

La primera de ellas es un tema extraído de la literatura francesa, concretamente de la poesía épica, del siglo XII. A un caballero de alto rango del imperio latino de Constantinopla, nombrado Pierre de Bracheux, célebre por su habilidad en guerrear, le enviaron los valacos y cumanos (Blaks et Commain, en el texto francés), a instancia de su jefe Juan, una invitación para que visitara la corte búlgara. Unas líneas más abajo R. De Clari apunta el diálogo supuestamente habido entre el caballero franco y Juan. El monarca búlgaro pregunta al caballero por qué razón había querido abandonar sus tierras lejanas y cuál era la causa que lo impulsó a guerrear contra los bizantinos. Pierre de Bracheux le contestó muy naturalmente que ¡la causa era la destrucción de Troya! Porque:

Troies fu a nos anchiseurs, et chil qui en escaperent si s'en vinrent manoir la dont nous sommes venu; et pour che que fu a nos anchisieurs, sommes nous chi venu conquerre tere ${ }^{38}$.

Es chocante que nuestro escritor franco prefiera desterrar una historia legendaria que hace referencia a los orígenes troyanos de los galos. Es muy probable que esta inserción se hizo cuando R. de Clari estaba ya en su patria. En todo caso, el escritor francés nos hace pensar con esta mención los regionalismos surgidos en el siglo XIII. También esto nos conduce a una práctica cro-

fructuosa (...) Cuius utilitas potest esse triplex, scilicet peccatorum remissio, gratie collatio et glorie exhibitio.", I. da Varazze, Legenda aurea, pp. 336 y 343 respectivamente.

38 R. de Clari, La conquête de Constantinople, p. 202, líneas 26-29. 
nológica existente entre los autores occidentales de la época, edificada sobre un sueño del profeta Daniel ${ }^{39}$ : la división del tiempo entre imperios que se suceden entre sí. Conforme a esta teoría el pueblo elegido de la actualidad es la culminación de una serie de pueblos que habían podido tener bajo su control el dominio mundial. Así, se empieza por los pueblos orientales, los cusitas, los macedonios, los griegos etc. Luego, pasa por los romanos y llega hasta el momento presente ${ }^{40}$. La conclusión está irrevocablemente en el Occidente. Es la bien conocida translatio imperii ${ }^{41}$. Esta inmersión en el pasado para encontrar una estirpe legendaria conlleva la idea de una repetición cíclica, ya que el pueblo de la actualidad, en este caso los francos, se conduce al principio de la Historia dominando otra vez el mundo. Y el principio está colocado a su final.

Este tipo de coincidencia produce la sensación del cumplimiento de los tiempos. Pero, esta noción es primordialmente contradictoria, si bien este parámetro no importaba mucho al hombre medieval. Expliquémonos. Paralelamente a esta idea existía el tiempo escatológico. Sin embargo el tiempo escatológico no se repite porque es lineal. En lugar de retroceder, evoluciona desde la caída del hombre hasta su Juicio Final. La leyenda pues continua sin parar. Más concretamente, la conquista de la ciudad fasta y su "rotura" no afectaron la necesidad vital del imaginario. Se siguió pensando en una tierra de abundancia, en un lugar-fetiche. Amén de esto, la captación preexistida se re-nutrió por las de nuevo elaboradas profecías, los nuevos mitos etc. P. Alphandéry y A. Dupront escriben genuinamente:

A través o al lado, se descubre una nueva conciencia del Oriente (...) por la transposición inmediata de esta realidad presentida en las explicaciones que provienen del mitismo histórico del Oriente mediterráneo. ${ }^{42}$.

En la segunda digresión que hemos escogido por el texto de R. de Clari, nos encontramos en el sitio de Tesalónica por parte de Juan de los búlgaros (Octubre de 1207). Recordemos que esa ciudad había formado la capital del reino de Tesalónica, cuyo monarca era Bonifacio de Montferrato.

\footnotetext{
39 Véase A. Liakos, Utopian and historical, pp. 4-8, texto disponible en: http://www.culturahistorica.es/liakos/utopian_and_historical_thinking.pdf, [consulta: 01/06/2012].

40 Reproducimos aquí el esquema encontrado en el libro de P. J. Alexander, The byzantine apocalyptic tradition, pp. 18, 40, 158, 162.

${ }^{41}$ J. Le Goff, Medieval civilization, p. 171. Sobre el origen del concepto y su itinerario hasta que llegó a establecerse completamente dentro del molde conceptual de los filósofos de la historia occidentales, véase J. Ward, The theory, pp. 1-21.

42 P. Alphandéry, A. Dupront, La cristiandad, p. 68; Sobre la procedencia de esta literatura apocalíptica, su razón de ser y su uso véase P.J. Alexander, The byzantine apocalyptic tradition, pp. 8, 16.
} 
Tras la muerte del rey longobardo la única persona que quedó en la ciudad para gobernar era su esposa. Así pues, el ejército de los búlgaros se preparó para arremeter contra la capital del reino, que disponía solo de una guardia. La reacción fue inmediata. El cuerpo de San Demetrio, que es el santopatrón de Tesalónica, segregó grandes cantidades de aceite sagrado. Y una mañana apareció en la tienda de Juan y lo mató con su lanza: Tesalónica se había salvado ${ }^{43}$.

Aquí tenemos, es patente, el caso de un milagro. Pero, ¿qué nos puede enseñar un episodio milagroso? Muchas cosas. En su análisis operaremos teniendo en cuenta las pautas de los teóricos de la literatura ${ }^{44}$, formulando conjeturas plausibles. Luego trataremos de entrelazar lo maravillosoliterario con lo histórico. Para comenzar, merece la pena notar que estamos ante un fenómeno sobrenatural religioso. Aparte de las demás leyendas y mitos provenientes sobre todo de los tiempos de la Antigüedad y el periodo helenístico, hay una parte de sucesos admirables bien enmarcados en la mentalidad totalizadora de la época: la de la religión cristiana. Esto puede quizás revelar un intento de control sobre lo generalmente extraordinario. Una categoría de lo maravilloso sobresale y se impone sobre sus fenómenos similares. Es la primacía de lo taumatúrgico. Como ha señalado J. Le Goff, el milagro siempre tiende a justificarse a través de la lógica de providencialismo ${ }^{45}$.

Muchas veces el elemento de la voluntad divina se expresa directamente al hombre medieval. Dios con un terremoto, con una plaga, con su voz o con lo que sea comunica su mensaje. Es un Dios enérgico. Aquí, sin embargo, tenemos el caso de un intermediario, de un campeón de la fe. Es un santo que, la verdad, actúa un poco por orgullo y no tanto por ejecutar el mandato del Señor. Este primer aspecto creemos que denota un intento de liberación del hombre oprimido por su director espiritual-moral, si bien nuestro autor franco es hermano de un clérigo y parece un hombre que, como es caballero, obedece disciplinadamente el orden jerárquico. La identificación sentimental de R. de Clari con alguien que obra por razones de honor puede avanzar más. San Demetrio es un santo militar ${ }^{46} \mathrm{y}$, de hecho, la lanza es el arma que lo caracte-

43 R. de Clari, La conquête de Constantinople, p. 210, líneas 1-15.

44 Por poner un ejemplo, véase el artículo sugerente de T. Todorov, Structural analysis, pp. 70-76. Merecería la pena que un historiador aplicara el análisis estructural a los aspectos literarios adecuados del texto de R. de Clari.

45 Es sugestivo el texto de J. Le Goff, Il meraviglioso, pp. 3-23.

46 En general, por parte de los francos se observa una preferencia hacia los cuentos hagiográficos y las reliquias pertenecientes a los santos militares. Un ejemplo elocuente es el caso de

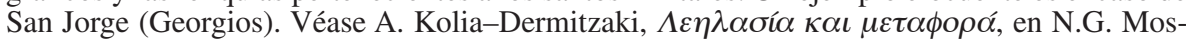

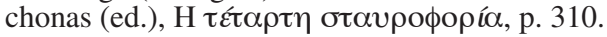


riza. En la iconografía se presenta montado a caballo pisoteando a su enemigo pagano $^{47}$.

Se trata pues, además de las otras interpretaciones existentes, del prototipo de la caballería: un jinete-héroe, el elegido de Dios, que no solo humilla a sus oponentes paganos sino que, gracias a su habilidad en la guerra, transmite mensajes severos hacia sus superiores que se quieren quedar con los frutos de su hazaña. También, ¿qué mejor podría hacer un caballero para demostrar su amor por la ciudad? El auto-sacrificio del militar por la prosperidad del espacio urbano - por su reino a fin de cuentas - es su momento de exaltación. Ya sólo a través de ese modo se puede legitimar - mantener socialmente. Es, todavía, una manera conveniente, una máscara bajo la cual R. de Clari, como caballero de segunda categoría, pudo a la vez describir los valores de su estamento, criticar a los que habían distribuido el botín injustamente, autoproponerse como el protegido de Dios dejando de lado a los expertos espirituales. Es impresionante, si lo pensamos un instante, que un extranjero que ha venido desde lejos se haya enterado tan bien de las tradiciones locales. Es, no cabe duda, la fuerza de lo oral, que en este caso prevalece sobre la información referente a la vida diaria del Medievo ${ }^{48}$.

Un incidente análogo lo encontramos también en el texto de nuestro autor bizantino. N. Choniates nos proporciona un caso de catástrofe sucedido en el campamento de los latinos. También estamos ante un sitio, esta vez de la ciudad rebelde de Didymoteicho en Tracia (otoño de 1205). Tras pasar el primer día de los ataques a la ciudad griega, los caballeros francos montaron sus tiendas al lado de un río que había allí cerca. Por la noche, repentinamente empezó un temporal. Por las grandes cantidades de agua que cayeron, el río se inundó tanto que cubrió todos los lados del valle que estaba a su lado. Pocos fueron los que se pudieron salvar ${ }^{49}$. El político bizantino nos da su explicación: la lluvia vino por el cielo, por lo tanto, es un signo de Dios. En este ejemplo tenemos la intervención del Señor por medio del agua.

Si bien N. Choniates era un hombre sesudo para su época, sabemos a través de su obra que no paraba de criticar y de reírse de los crédulos que acudían a los astrólogos y a los magos, aquí vemos una explicación muy ordinaria. Es la racionalización de lo sobrenatural o, dicho de otro modo, su referencia a la soteriología divina. Dios opera como el pastor que protege a su ganado. Está claro que, examinemos el occidente europeo o examinemos

47 Para información iconográfica y hagiográfica relativa a San Demetrio, véase H. Delehaye, Les légendes grecques, pp, 5-6, 103-109, 117.

48 Ibidem, p. 118. Un caso contrario en P. J. Alexander, The byzantine apocalyptic tradition, p. 2.

49 N. Choniatae, O City of Byzantium, p. 342, [624. 1-10]. 
el oriente, la Deidad es omnipresente, dispuesta siempre a defender a sus verdaderos seguidores. Esta índole beligerante denota la existencia de dos sociedades que según las ocasiones se mostraban intolerantes hacia el "otro" 50 . También, implica una cierta confusión de lo espiritual con lo terrenal. Es muy natural que Dios funcione como justiciero o defensor de sus amigos. Por lo demás, merece destacar la utilización del agua con su doble connotación: purificadora y cataclísmica. También la opción de apoyarse en la mitología.

Los caballeros, junto con sus caballos, pasan por un camino acuático, el río Aqueronte, hacia el final, hacia la muerte. Más concretamente,

La Mort est un voyage et le voyage est une mort. «Partir, c'est mourir un peu». Mourir, c'est vraiment partir et l'on ne part bien, courageusement, nettement, qu'en suivant le fil de l'eau, le courant du large fleuve.

nos recuerda el filósofo francés G. Bachelard ${ }^{51}$. Sin embargo, como se sabe por la tradición mitológica conservada, para poder atravesar ese río el alma tenía primero que haber pagado a su conductor. Así, podríamos entender el pago realizado como una confirmación del estado cambiante. Todavía, antes de seguir el camino del agua, estamos ante una situación intermedia, entre la vida y la muerte. Todo ese proceso que ha de suceder en el río Aqueronte se podría ver como un "rito de pasaje" 52 . Es muy posible que el autor bizantino haya tratado de disminuir algo la dignidad caballeresca, presentando a los francos como seres frágiles y clandestinos. Además, esta idea se corrobora si pensamos que la muerte precipitada y/o turbulenta era para la mentalidad del cristiano medieval signo de maldición. Este último punto se enfatizó aún más, combinado con la imagen de la entrega de la deuda debida antes de poder morir tranquilamente.

Otro inciso realizado por N. Choniates que merece, según nuestra opinión, ser analizado es lo que sigue: los caballeros occidentales, inmediatamente después de la Partitio Terrarum Imperii Romaniae, van a conquistar en Grecia los sitios correspondientes a cada uno. El jefe de esa expedición es, otra vez, el gran señor feudal Bonifacio de Montferrato. Todos van a caballo. Empiezan por Tesalónica hasta llegar al sur del Peloponeso. Se mueven tan rápidamente que se comparan con un ave impetuosa. No hay quien les pueda resistir. Sucesivamente, pues, caen todas las "grandes" ciudades griegas: Tebas, Corinto, Atenas, etc. Creemos que la frase clave del pasaje aquí tocado

50 Unas de las ópticas proyectadas de los bizantinos sobre los latinos en P. Gounarides,

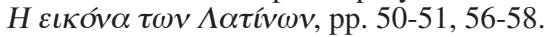

${ }_{51}$ G. Bachelard, L'eau et les rêves, p. 102.

52 A. van Gennep, The rites of passage. 
es la que califica a los latinos: $y$ [el ejército de los caballeros] no adelantaba a pie, sino que avanzaba sobre el devenir de la Historia, como si fuera un ave, un ser plasmado por el aire ${ }^{53}$. En primer lugar, trataremos de explicar la imagen bien elaborada del caminar raudamente sobre el flujo de los acontecimientos de la "Historia".

Tenemos la impresión de que aquí se revela una noción muy concreta sobre la vida del hecho histórico. La manifestación de que los latinos avanzaban más rápidamente que la misma Historia es un esquema retórico excesivo, una hipérbole. Creemos que esto denota que los sucesos "superficiales" duran muy poco, se suceden entre sí en poco tiempo. Pero esto parece obvio y es algo que no ha cambiado tampoco en nuestros días. Igual aquí con la velocidad que se les atribuye a los sucesos terrenales se les quiere quitar importancia, ya que el destino real de la Historia, su propósito más bien, es su conclusión: el Juicio Final y la Resurrección o, dicho en otras palabras, la Salvación. Bajo este prisma, pues, se podría decir que N. Choniates tenía en el fondo, cuando escribía esos versos, el plan de la teleología divina. Si es así, los caballeros que tratan de alterar la Historia cometen hybris ${ }^{54}$. Esta conjetura se puede defender si tomamos en cuenta el comienzo del razonamiento del bizantino. Este es así como sigue: [los bárbaros] revolotean más rápidamente que el ala de la Historia ${ }^{55}$. Para nuestro autor, como en general para todos los hombres de letras - pensadores ortodoxos ${ }^{56}$ que habían profundizado en la confesión cristiana, los acontecimientos profanos cesan de ser absolutamente profanos. Se abren entonces a una interpretación analógica y tipológica ${ }^{57}$.

En segundo lugar, parece que se relaciona la rapidez vertiginosa de los atacantes con su efectividad. Es como si el bizantino quisiera decir que han conquistado de inmediato todas las ciudades porque han arremetido enseguida. En lo que concierne a este silogismo, a lo mejor podemos encontrar la percepción existente sobre el tiempo en el Medievo. De un hecho militar se revela que el que siempre gana es el que actúa rápidamente, imponiendo su primacía sobre el espacio.

53 Traducción directamente del texto original. Véase, N. Choniatae, Historia, p. 610. 4-5.

54 P. Gounarides, $H \varepsilon \iota \kappa \delta ́ v \alpha \tau \omega v \Lambda \alpha \tau i v \omega v$, p. 54, donde se presenta la utilización del esquema de la hybris (latinos vencedores - bizantinos vencidos - soberbia latina por sus victorias - comisión de hybris) por parte del autor bizantino. Desconocemos si P. Gounarides tiene como punto de partida para su comentario el mismo pasaje que acabamos de analizar en el grueso de nuestro texto.

55 N. Choniatae, Historia, p. 610.1-2.

56 Aquí, es obvio, no nos referimos al dogma ortodoxo. La palabra se utiliza con su sentido más amplio.

57 K. Löwith, El sentido de la historia, p. 209. 


\section{CONCLUSIONES}

Tras este repaso ecléctico que hemos realizado, pensamos que ahora conviene esquematizar. Las fuentes aquí abordadas, que nos dejan evidencia exacta sobre la toma de Constantinopla por los latinos en 1204 y su posteridad, parece que convergen en un punto, pese a que estén compuestas por dos hombres de diferente nivel cultural: la tesis de lo fantasioso al lado de la narración de los hechos históricos. Mejor dicho, hemos visto que tanto los caballeros francos como los bizantinos del siglo XIII recurrieron, por razones diferentes, al remedio del imaginario. Esto, por una parte, era algo común para la época, que llegó a reflejarse incluso en la historiografía del pleno medievo: En dichos textos [historiográficos], lo "maravilloso" abarca desde lo más simple hasta lo más absurdo e increíble, complicándose sobre manera en la hagiografía, corroboran C. Orcástegui y E. Sarasa ${ }^{58}$. Por otra parte, en una visión más amplia, este fenómeno tuvo consecuencias divergentes para nuestros protagonistas. Los franceses gracias a su hazaña conseguida pudieron saborear la leyenda. Optaron por seguir viviendo dentro de ella y sobre todo por eso, en 1261, se vieron forzados a abandonar la capital de su imperio ${ }^{59}$. Sin embargo, trasladaron a sus compatriotas del Occidente europeo un espíritu de positivismo. Este espíritu, combinado con la progresiva asimilación del mundo a través del racionalismo creciente contribuyó a la auto-estima del individuo y al descubrimiento de su funcionalismo en pro del todo social ${ }^{60}$. Era una perspectiva que, aunque tenía que lanzarse contra un status bien arraigado, se dirigía hacia el futuro. Gracias al pensamiento utópico, pues, se puede avanzar.

En cuanto al testimonio del bizantino N. Choniates, generalmente hablando, podríamos apreciar que este tipo de refugio bajo la mitología y la leyenda, que aparece muy a menudo en su obra, funcionaba como sistema defensor. En la sociedad bizantina esa práctica se daba cuando los habitantes de Romania periclitaban política y socialmente ${ }^{61}$. Creemos que no es casual que

58 C. Orcástegui, E. Sarasa, La historia en la Edad Media, p. 51.

59 "The Latin's disdain for political and diplomatic realities brought disaster upon them". D.E. Queller, The fourth crusade, p. 151. También, p. 153.

${ }^{60}$ No hay que perder de vista que esta dirección la indicó primeramente el feudalismo. La relación obligación - derecho recalcaba la especificidad de cada uno en la sociedad. Véase al respecto A. Gurevich, Why am I not a byzantinist?, en Homo Byzantinus, pp. 94-95. Para una tesis metodológicamente contraria, véase E.H. Carr, Society and the individual, en What is history?, pp. 31-55.

${ }_{61}$ Nos referimos, creemos que está claro, sobre todo a los problemas estructurales de Bizancio, que empiezan a aparecer desde ya el siglo XI. Por lo tanto, para nada no se insinúa aquí una explicación de la decadencia bizantina durante la baja Edad Media atribuida a la toma de Constantinopla en 1204. 
la encontremos sobre todo en el espacio geográfico coincidente con Constantinopla, por el papel egocéntrico de la ciudad. Sus habitantes, una vez más, empiezan a buscar sus orígenes en un pasado idealizado - inventado y bastante remoto que les va a mantener dentro de una inercia oscilante. Paralelamente a esto, los años siguientes la influencia espiritual de los monjes bizantinos empezaba a dejar una profunda impronta. Es la era en la que esos zelotes de la fe ortodoxa deslindan las diferencias dogmáticas e identitarias con los que están al otro lado europeo. Con la refutación tenaz por parte de los monjes "demagogos" de Bizancio en cuanto a la cuestión teológica de filioque (alrededor de 1274, II sínodo de Lyons) $)^{62}$, se decanta hacia el misticismo, algo que, sin duda, aparta la atención del hombre de los asuntos terrenales ${ }^{63}$. Todo lo que no se puede lograr en la vida real se alcanza mediante la imaginación. En 1453, con el peligro de una pérdida perpetua, aparece por primera vez la tradición literaria que se refiere al rey durmiente. Esperaban su retorno mágico ${ }^{64}$. Y a aquél personaje lo despertaron las voces nacionalistas del siglo XIX. Por culpa del pensamiento utópico, se puede retroceder.

Por último, con las profecías creadas en Oriente, las cuales supuestamente habían predeterminado la venida de los occidentales ${ }^{65}$, parece como si esos hombres se hubieran dejado llevar patéticamente por el hado. Si pensamos un instante, a lo largo de la historia de Constantinopla, se eligió tal solución teleológica y de comportamiento por la índole propia de la capital del imperio bizantino (urbanización excesiva en contraposición con las provincias periclitadas, auto-enaltecimiento y auto-separación cultural de los demás ${ }^{66}$ ). Aparte de eso, ya desde la época de su fundador Constantino había una fobia sobre la destrucción futura de la capital renombrada. Y eso porque, desde el principio, dicha ciudad se vio como una apuesta. Apuesta que parecía al principio no operativa. Sus vastas murallas, por poner el ejemplo elocuente de G. Dagron, precedieron a su explosión demográfica ${ }^{67}$. Por inferencia, hablar de un porvenir oscuro significa afirmar las pretensiones sobre lo eterno. Eran los primeros indicios de la noción extrahistórica.

${ }^{62}$ Por supuesto, polémica oriunda de las escisiones y discrepancias existentes entre los eclesiásticos bizantinos: T.M. Kolbada, Byzantine perceptions, pp. 119-121, 131-132, 135, 137, 139.

63 H.-G. Beck, Theologie, en Das byzantinische jahrtausend, pp. 163-206.

64 O un "Segundo Advenimiento". Véase al respecto, D.M. Nicol, The immortal emperor, pp. 74-76, 89-90, 98-104, 107; E. Ayensa, Folclore, pp. 179-205; F. Graus, Social utopias, p. 17. Para información en cuanto al concepto (origen, circularidad, re-elaboración etc.) del último emperador de los romanos consúltese P.J. Alexander, The byzantine apocalyptic tradition, pp. 4, 21, 151, 154-157.

65 Un futuro siniestro en la mayoría de las veces.

66 U otra contradicción patente que se relaciona con nuestro tema: la ciudad más poblada del Medievo sitiada por un ejercito pequeño.

67 G. Dagron, Naissance d'une capitale, pp. 9, 35; idem, Constantinople imaginaire. 


\section{BIBLIOGRAFÍA CITADA}

\section{FUENTES PRIMARIAS}

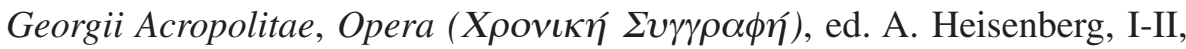
Lipsia, 1903 [reedición por P. Wirth, Stuttgart, 1978].

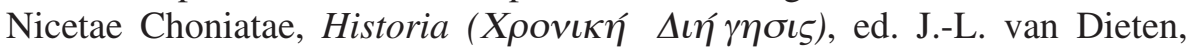
[CFHB, XI], Berlín - Nueva York, 1975; O City of Byzantium, Annals of Niketas Choniates, trad. H. J. Magoulias, Detroit, Wayne State University Press, 1984, pp. 321-362.

Robert de Clari, La conquête de Constantinople, trad. J. Dufournet [édition bilingue], Paris, Honoré Champion, 2004; The conquest of Constantinople, trad. E. H. McNeal, Nueva York, Columbia University Press, 2005.

Iacopo da Varazze, Legenda aurea, ed. G. P. Maggioni, vol. I, Florencia, Sismel Edizioni del Galluzzo, 1998.

Geoffroy de Villehardouin, Villehardouin's Chronicle of the fourth crusade and the conquest of Constantinople, en Villehardouin and De Joinville, Memoirs of the Crusades, trad. Sir F. T. Marzials, Londres, 1965, pp. 1-133.

\section{OBRAS MODERNAS}

Abrams, Philip, History, sociology, historical sociology, "Past and Present" 87/1 (1980), pp. 3-16.

Alexander, J. Paul, The byzantine apocalyptic tradition, Berkeley - Los Ángeles - Londres, University of California Press, 1985.

Alphandéry, Paul; Dupront, Alphonse, La cristiandad y el concepto de cruzada, vol. II: Las cruzadas (siglos XII-XIII), México, UTEH, 1962.

Angold, Michael, The fourth crusade: event and context, Harlow, Longman, 2003.

Ayensa, Eusebi, Folclore y nacionalismo griego. Ideologías en torno a la caída de la ciudad, "Erytheia" 24 (2003), pp. 179-205.

Bachelard, Gaston, L'eau et les rêves: essai sur l'imagination de la matière, París, Librairie José Corti, 1968.

Beck, Hans-Georg, Das byzantinische jahrtausend, Múnich, C.H.Beck, 1978.

Burckhardt, Jacob, The civilization of the Renaissance in Italy, Londres, Penguin Books, 1990.

Carr, H. Edward, What is history?, Londres, Penguin Books, 1987.

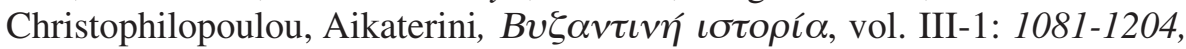
Atenas, 2001. 
Constable, Giles, The historiography of the crusades, en Laiou, A.E.; Mottahedeh, R.P. (eds.), The crusades from the perspective of Byzantium and the Muslim world, Washington D.C., Dumbarton Oaks Research Library and Collection, 2001, pp. 1-22.

Dagron, Gilbert, Naissance d'une capitale: Constantinople et ses institutions de 330 à 451, París, Presses Universitaires de France, 1974.

Dagron, Gilbert, Constantinople imaginaire, Études sur le recueil des Patria, París, Presses Universitaires de France, 1984.

Delehaye, Hippolyte, Les légendes grecques des saints militaires, Nueva York, Arno Press, 1975.

Eco, Umberto, Il feticismo nell'arte, "L'Espresso" (1967).

Frolow, Anatole, La déviation de la 4 e croisade vers Constantinople. Problème d'histoire et de doctrine, "Revue de l'histoire des religions" 145/2 (1954), pp. 168-187.

Geanakoplos J., Deno, Byzantine East and Latin West: two worlds of Christendom in Middle Ages and Renaissance, Nueva York, Blackwell, 1966.

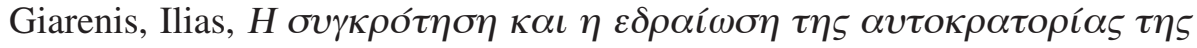

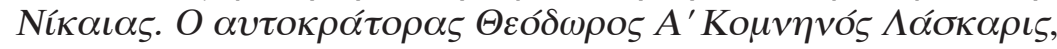

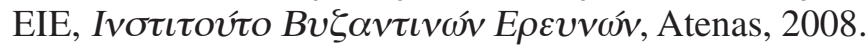

Gounarides, Paris, $H \varepsilon \iota \kappa \sigma o v \alpha \tau \omega v \Lambda \alpha \tau i v \omega v$, en Moschonas, N.G. (ed.), $H$

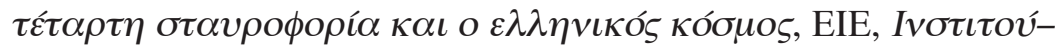

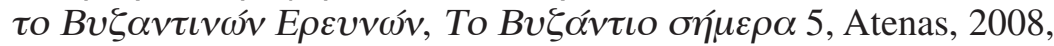
pp. 43-59.

Graus, František, Social utopias in the Middle Ages, "Past and Present" 38/1 (1967), pp. 3-19.

Guenée, Bernard, Histoires, annales, chroniques: essai sur les genres historiques au Moyen Age, "Annales. Histoire, Sciences Sociales" 28/4 (1973), pp. 997-1016.

Gurevich, Aaron, Historical anthropology of the Middle Ages, Cambridge, Polity, 1992.

Gurevich, Aaron, Why am I not a byzantinist?, en Homo Byzantinus: Papers in honor of Alexander Kazhdan, "Dumbarton Oaks Papers", 46 (1992), pp. 89-96.

Harris, Jonathan, Distortion, divine providence and genre in Niceras Choniates's account of the collapse of Byzantium 1180-1204, "Journal of Medieval History", 26/1 (2000), pp. 19-31.

Harris, Jonathan, Byzantium and the crusades, Lancaster, Continuum International Publishing Group, 2006.

Hunger, Herbert, Byzantinische geisteswelt, Ámsterdam, A.M. Hakkert, 1967. Kazhdan, Alexander, Latins and Franks in Byzantium: perception and reality from the eleventh to the twelfth century, en Laiou, A.E.; Mottahedeh, 
R.P. (eds.), The crusades from the perspective of Byzantium and the Muslim world, Washington D.C., Dumbarton Oaks Research Library and Collection, 2001, pp. 83-100.

Kolbada, M. Tia, Byzantine perceptions of Latin religious «errors»: themes and changes from 850 to 1350, en Laiou, A.E.; Mottahedeh, R.P. (eds.), The crusades from the perspective of Byzantium and the Muslim world, Washington D.C., Dumbarton Oaks Research Library and Collection, 2001, pp. 117-143.

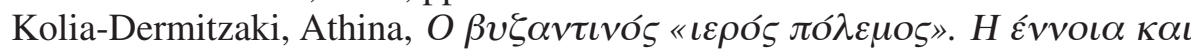

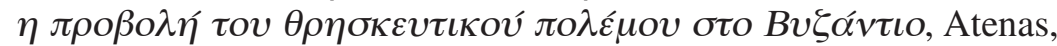

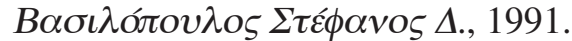

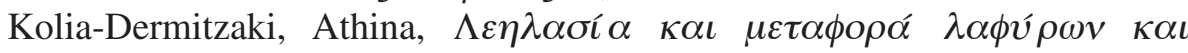

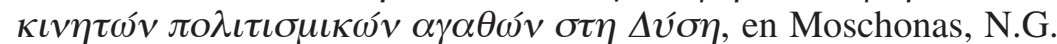

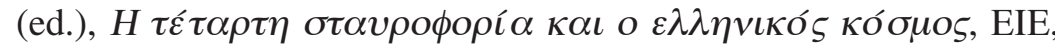

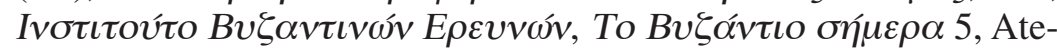
nas, 2008, pp. 299-326.

Le Goff, Jacques, Guerriers et bourgeois conquérants. L'image de la ville dans la littérature française au XIIe siècle, en Culture, science et développement: contribution à une histoire de l'homme. Mélanges en l'honneur de Charles Morazé, Tolosa, Privat, 1979, pp. 113-136.

Le Goff, Jacques, Il meraviglioso e il quotidiano nell' Occidente medievale, Roma - Bari, Laterza \& Figli, 1983.

Le Goff, Jacques, Medieval civilization 400-1500, Oxford, Blackwell,1990.

Liakos, Antonis, Utopian and historical thinking: interplays and transferences, "Historein" 7 (2007), pp. 1-50 [la paginación adoptada es la que aparece en el pdf disponible en la red]: http://www.culturahistorica.es/ liakos/utopian_and_historical_thinking.pdf, [consulta: 01/06/2012].

Lotman, M. Iuri, La semiótica de la cultura y el concepto de texto, "Entretextos. Revista Electrónica Semestral de Estudios Semióticos de la Cultura" 2 (2003), http://www.ugr.es/ mcaceres/entretextos/pdf/entre2/ escritos/escritos2.pdf, [consulta: 20/07/2011].

Löwith, Karl, El sentido de la historia: implicaciones teológicas de la filosofía de la historia, Madrid, Aguilar, 1973.

Madden, F. Thomas (ed.), The fourth crusade: event, aftermath and perceptions, Papers from the sixth conference of the society for the study of the crusades and the Latin East, Istanbul, Turkey, 25-29 August 2004, Bodmin, Ashgate Publishing, 2008.

Mavromatis, Leonidas, Historia bizantina e historia, "Erytheia" 11-12 (19901991), pp. 65-70.

Meschini, Marco, The 'four crusades' of 1204, en Madden, Th.F. (ed.), The fourth crusade: event, aftermath and perceptions, Papers from the 
sixth conference of the society for the study of the crusades and the Latin East, Istanbul, Turkey, 25-29 August 2004, Bodmin, Ashgate Publishing, pp. 27-42.

Mitre, Emilio, Historiografía y mentalidades históricas en la Europa Medieval, Madrid, Editorial de la Universidad Complutense, 1982.

Nicol, M. Donald, The fourth crusade and the Greek and Latin empires 12041261, en Byzantium: Its ecclesiastical history and relations with the western world, Londres, Variorum Reprints, 1972, vol. II, pp. 275-330.

Nicol, M. Donald, The immortal emperor: the life and legend of Constantine Palaiologos, last emperor of the Romans, Cambridge, Cambridge University Press, 1992.

Orcástegui, Carmen; Sarasa, Esteban, La historia en la Edad Media. Historiografía e historiadores en Europa Occidental: siglos V-XIII, Madrid, Cátedra, 1991.

Ostrogorsky, Georg, Historia del estado bizantino, Madrid, Akal Universitaria, 1984.

Philips, Jonathan, The fourth crusade and the sack of Constantinople, "History Today" 54/5 (2004), pp. 21-28.

Queller, E. Donald, The fourth crusade: the conquest of Constantinople, 1201 1204, Filadelfia, University of Pennsylvania Press, 1977.

Runciman, Steven, A history of the crusades, v. III: The kingdom of Acre and the late crusades, Cambridge, Cambridge University Press, 1951.

Runciman, Steven, Mistra, Londres, Thames \& Hudson, 1980.

Simpson, J. Alicia, Before and after 1204: The versions of Niketas Choniates' Historia, "Dumbarton Oaks Papers" 60 (2006), pp. 189-221.

Stouraitis, Ioannis, Jihād and crusade: byzantine positions towards the notions of "holy war", "Byzantina Symmeikta" 21 (2011), pp. 11-63.

Swietek, R. Francis, Gunther of Pairis and the Historia Constantinopolitana, "Speculum" 53/1 (1978), pp. 49-79.

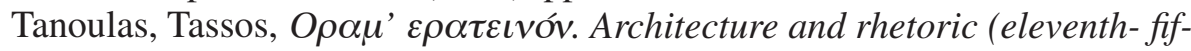
teenth centuries), en Angelidi, C. (ed.), Byzantium matures. Choices, sensitivities, and modes of expression (eleventh to fifteenth centuries), NHRF, Institute for Byzantine Research, International Symposium 13, Atenas, 2004, pp. 313-339.

Todorov, Tzvetan, Structural analysis of narrative, "Novel: a forum on fiction" 3/1 (1969), pp. 70-76.

Van Gennep, Arnold, The rites of passage, Londres, Routledge, 2004.

Ward, Joseph, The theory of the four monarchies. Opposition history under the Roman empire, "Classical Philology" 35/1 (1940), pp. 1-21.

Fecha de recepción del artículo: enero 2012

Fecha de aceptación y version final: junio 2012

ANUARIO DE Estudios Medievales, 43/2, julio-diciembre 2013, pp. 695-716

ISSN 0066-5061, doi:10.3989/aem.2013.43.2.07 